\title{
Modeling of solid-particle effects on bubble breakage and coalescence in slurry bubble columns
}

\author{
Adam Mühlbauer, Mark W. Hlawitschka (ه), Hans-Jörg Bart
}

Lehrstuhl für Thermische Verfahrenstechnik, Technische Universität Kaiserslautern, Gottlieb-Daimler-Straße 44, 67663 Kaiserslautern, Germany

\begin{abstract}
Solid particles heavily affect the hydrodynamics in slurry bubble columns. The effects arise through varying breakup and coalescence behavior of the bubbles with the presence of solid particles where particles in the micrometer range lead to a promotion of coalescence in particular. To simulate the gas-liquid-solid flow in a slurry bubble column, the Eulerian multifluid approach can be employed to couple computational fluid dynamics (CFD) with the population balance equation (PBE) and thus to account for breakup and coalescence of bubbles.

In this work, three approaches are presented to modify the breakup and coalescence models to account for enhanced coalescence in the coupled CFD-PBE framework. The approaches are applied to a reference simulation case with available experimental data. In addition, the impacts of the modifications on the simulated bubble size distribution (BSD) and the applicability of the approaches are evaluated. The capabilities as well as the differences and limits of the approaches are demonstrated and explained.
\end{abstract}

\section{Keywords}

breakup and coalescence

CFD simulation

population balance equation

slurry bubble column

solid-particle effect

Article History

Received: 27 February 2020

Revised: 4 May 2020

Accepted: 14 May 2020

Research Article

(c) The Author(s) 2020

\section{Introduction}

A variety of chemical, petrochemical, biochemical, and metallurgical processes are carried out in slurry bubble columns on the industrial scale (Shah et al., 1982; Deckwer and Schumpe, 1985; Fan, 1989). Well-known examples can be found in the hydrogenation of carbon monoxide for the production processes of hydrocarbons (e.g., Fischer-Tropsch or methanol synthesis). The description of the complex hydrodynamics in gas-liquid-solid multiphase systems became of special research interest in recent years (Ojima et al., 2014; Sarhan et al., 2018). In particular, the determination of the BSD and the estimation of the volume-specific interfacial area are of major importance to model chemical processes with mass transfer.

The solid-particle phase affects the hydrodynamics in the column drastically, and especially the effect on the total gas holdup in the apparatus has been stated repeatedly (Krishna et al., 1997; Luo et al., 1999; Li and Prakash, 2000; Vandu and Krishna, 2004). Empirical correlations for the gas holdup can be found collated in the work of Behkish et al. (2006). Depending on the particle size, adverse effects of the solid-particle phase occur. Particles with diameters in the sub-millimeter range (i.e., microparticles) lead to a decrease, whereas larger particles may increase the gas holdup (Sarhan et al., 2018). Microparticles change the effective density and viscosity of the slurry and promote bubble coalescence (Krishna et al., 1997; Li and Prakash, 2000). Intensified coalescence was observed in the presence of hydrophobic (van der Zon et al., 2002), as well as of hydrophilic particles (Ojima et al., 2014). In contrast, large particles with diameters in the millimeter range may lead to breakup when colliding with bubbles and result in an increase of the gas holdup (Fan et al., 2007). Amongst latest experimental investigations, detailed studies can be found on the characterization of the gas-phase dynamics (Tyagi and Buwa, 2017; Mokhtari and Chaouki, 2019; Sines et al., 2019) and solid-particle concentration distributions (MacIntyre et al., 2017; Abdullah, 2019) inside slurry bubble columns.

The simulation of the gas-phase dynamics with bubble breakage and coalescence can be achieved by solving the population balance equation (PBE), wherein the physical phenomena are modeled in the source terms. The PBE is

$\bowtie$ mark.hlawitschka@mv.uni-kl.de 


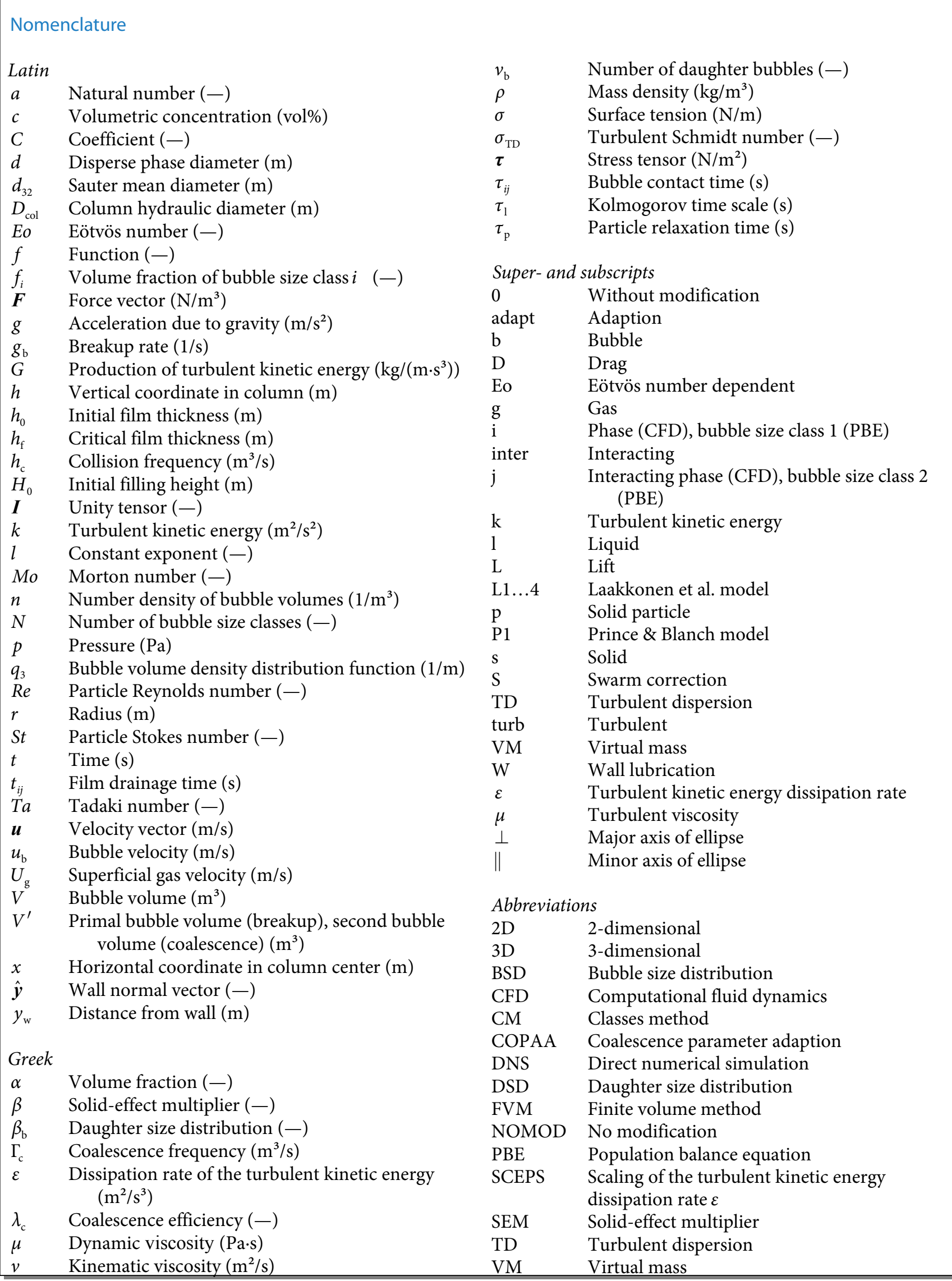


coupled with the transport equations of CFD and forms an appropriate framework for multiphase flow simulation in an apparatus. An overview of slurry bubble column simulations can be found in literature and are listed in the work of Mühlbauer et al. (2019), in which also correlating experimental literature data for validation is given. In very recent literature, the influences of the slurry apparent density and viscosity were investigated by An et al. (2020). They found that these parameters cannot explain the effects of solid particles on bubble breakup and coalescence. Furthermore, they studied two of the approaches presented also in this paper but applied to another reference case for intermediate solid-particle concentrations up to $10 \mathrm{vol} \%$. They approve the applicability and recommend an approach combined with an attenuation factor of the turbulent dissipation rate. However, the authors also state that further verification is needed for other systems and operating points. Syed et al. (2018) applied different combinations of breakup and coalescence models in slurry bubble column simulations with solid-particle concentrations up to $c_{\mathrm{s}}=$ $14 \mathrm{vol} \%$ and found the limitations of the models especially at a high superficial gas velocity $U_{\mathrm{g}}=0.08 \mathrm{~m} / \mathrm{s}$. Zhou et al. (2017) introduced a factor to reduce the drag between the bubbles and the liquid-phase when solid particles are present similar to a swarm correction. They found that the approach is able to achieve improved gas holdup simulation results also at high superficial gas velocities up to $U_{\mathrm{g}}=0.3 \mathrm{~m} / \mathrm{s}$ and solid-particle concentrations up to $c_{\mathrm{s}}=40 \mathrm{vol} \%$ where heterogeneous flow structures occur. Further research activities investigate the coupling of the PBE with mass transfer equations (Vik et al., 2018) or develop modeling approaches for the formation of a froth layer (Sarhan et al., 2018) in slurry bubble columns. The latter mentioned are of special interest and are relevant for industrial applications.

The present work focuses on modeling the multiphase fluid dynamics with the coupled CFD-PBE approach in slurry bubble columns to account for enhanced bubble coalescence due to the presence of solid microparticles. Therefore, the breakup and coalescence models in the PBE are modified when solid particles are present. Three approaches found in literature are transferred to the same gas-liquid-solid system with available experimental data for verification (Ojima et al., 2014). All approaches were tested and compared for two superficial gas velocities $U_{\mathrm{g}}=0.020$ and $0.034 \mathrm{~m} / \mathrm{s}$ and a wide range of solid-particle concentrations up to $c_{\mathrm{s}}=40$ vol\%.

\section{Governing equations}

The CFD simulations are based on the balance equations of mass and momentum for all three phases (gas, liquid, solid) and the PBE is solved for the gas-phase. The equations and closures are presented in the following section.

\subsection{Multifluid model}

The derivation of the multifluid model used in this work can be found in literature (Jakobsen, 2014) and is frequently applied to simulate bubbly flows (Tabib et al., 2008; Rzehak and Kriebitzsch, 2015). According to the Eulerian multifluid approach the conservation equations of mass and momentum are written as

$$
\frac{\partial\left(\alpha_{i} \rho_{i}\right)}{\partial t}+\nabla \cdot\left(\alpha_{i} \rho_{i} \boldsymbol{u}_{i}\right)=0
$$

and

$$
\begin{gathered}
\frac{\partial\left(\alpha_{i} \rho_{i} \boldsymbol{u}_{i}\right)}{\partial t}+\nabla \cdot\left(\alpha_{i} \rho_{i} \boldsymbol{u}_{i} \otimes \boldsymbol{u}_{i}\right) \\
=-\alpha_{i} \nabla p+\nabla \cdot\left(\alpha_{i} \boldsymbol{\tau}_{i}\right)+\alpha_{i} \rho_{i} \boldsymbol{g}+\boldsymbol{F}_{i, j}^{\text {inter }}
\end{gathered}
$$

for all $i$ phases (gas, liquid, and solid). The phase volume fractions $\alpha_{i}$ fulfill the constraint:

$$
\alpha_{\mathrm{g}}+\alpha_{1}+\alpha_{\mathrm{s}}=1
$$

The stress tensor $\boldsymbol{\tau}_{i}$ for Newtonian fluids is

$$
\boldsymbol{\tau}_{i}=\mu_{i}\left(\nabla \boldsymbol{u}_{i}+\left(\nabla \boldsymbol{u}_{i}\right)^{\mathrm{T}}-\frac{2}{3} \boldsymbol{I}\left(\nabla \cdot \boldsymbol{u}_{i}\right)\right)
$$

Two cases are distinguished for the interphase exchange term $\boldsymbol{F}_{i, j}^{\text {inter }}$ between phases $i$ and $j$. The expression for the gas-liquid interactions is

$$
\boldsymbol{F}_{\mathrm{g}, \mathrm{l}}^{\text {inter }}=-\boldsymbol{F}_{\mathrm{l}, \mathrm{g}}^{\text {inter }}=\boldsymbol{F}_{\mathrm{b}}^{\mathrm{D}}+\boldsymbol{F}_{\mathrm{b}}^{\mathrm{L}}+\boldsymbol{F}_{\mathrm{b}}^{\mathrm{W}}+\boldsymbol{F}_{\mathrm{b}}^{\mathrm{TD}}+\boldsymbol{F}_{\mathrm{b}}^{\mathrm{VM}}
$$

Rzehak et al. (2015) recommend with the baseline model for bubbly flows to account for all the types of forces written in Eq. (5). The applied models are described for the gas-liquid closures in the following.

The general expression for the drag force is

$$
\boldsymbol{F}^{\mathrm{D}}=-C_{\mathrm{D}} \alpha_{\mathrm{g}} \frac{3}{4 d_{\mathrm{b}}} \rho_{\mathrm{l}}\left|\boldsymbol{u}_{\mathrm{g}}-\boldsymbol{u}_{1}\right|\left(\boldsymbol{u}_{\mathrm{g}}-\boldsymbol{u}_{1}\right)
$$

where $C_{\mathrm{D}}$ is often modified and applied in Eq. (6) with an additional swarm correction function dependent on the gas volume fraction $\alpha_{\mathrm{g}}$ :

$$
C_{\mathrm{D}}^{\mathrm{S}}=C_{\mathrm{D}} \cdot f\left(\alpha_{\mathrm{g}}\right)
$$

The model of Tomiyama et al. (1998) for a contaminated system is applied for the drag coefficient:

$$
C_{\mathrm{D}}=\max \left[\frac{24}{R e}\left(1+0.15 R e^{0.687}\right), \frac{8}{3} \frac{E o}{E o+4}\right]
$$

The particle or bubble Reynolds number is

$$
R e=\frac{\rho_{1}\left|\boldsymbol{u}_{\mathrm{g}}-\boldsymbol{u}_{1}\right| d_{\mathrm{b}}}{\mu_{1}}
$$

and the correlation for the swarm correction is according to Tomiyama et al. (1995): 


$$
f\left(\alpha_{\mathrm{g}}\right)=\left(1-\alpha_{\mathrm{g}}\right)^{3-2 l}
$$

with $l=1$ (Jiang et al., 2016).

The lift force is

$$
\boldsymbol{F}^{\mathrm{L}}=C_{\mathrm{L}} \alpha_{\mathrm{g}} \rho_{\mathrm{l}}\left(\boldsymbol{u}_{1}-\boldsymbol{u}_{\mathrm{g}}\right) \times \operatorname{rot}\left(\boldsymbol{u}_{1}\right)
$$

where the model according to Tomiyama et al. (2002) for the lift coefficient is

$$
C_{\mathrm{L}}=\left\{\begin{array}{lr}
\min \left[0.288 \tanh (0.121 R e), f\left(E o_{\perp}\right)\right], E o_{\perp}<4 \\
f\left(E o_{\perp}\right), & 4<E o_{\perp}<10 \\
-0.27, & 10<E o_{\perp}
\end{array}\right.
$$

with the function:

$$
\begin{aligned}
& f\left(E o_{\perp}\right) \\
= & 0.00105 E o_{\perp}^{3}-0.0159 E o_{\perp}^{2}-0.0204 E o_{\perp}+0.474
\end{aligned}
$$

$E o_{\perp}$ is the Eötvös number calculated for the major axis $d_{\mathrm{b} \perp}$ of an ellipsoidal bubble and the general definition of Eo is

$$
E o=\frac{g\left(\rho_{1}-\rho_{\mathrm{g}}\right) d_{\mathrm{b}}^{2}}{\sigma}
$$

The model of Vakhrushev and Efremov (1970) was used to calculate the aspect ratio $E_{\mathrm{b}}=d_{\mathrm{b} \|} / d_{\mathrm{b} \perp}$ for the bubbles:

$$
E_{\mathrm{b}}=\left\{\begin{array}{lrl}
1, & T a \leq 1 \\
\left(0.81+0.206 \tanh \left(1.6-2 \log _{10} T a\right)\right)^{3}, & 1<T a \leq 39.8 \\
0.24, & 39.8<T a
\end{array}\right.
$$

with the Tadaki number:

$$
\mathrm{Ta}=\mathrm{ReMo} \mathrm{o}^{0.23}
$$

as a function of the Morton number:

$$
M o=\frac{\mu_{1}^{4} g\left(\rho_{1}-\rho_{\mathrm{g}}\right)}{\rho_{1}^{2} \sigma^{3}}
$$

The wall lubrication force can be expressed as

$$
\boldsymbol{F}^{\mathrm{W}}=C_{\mathrm{W}} \alpha_{\mathrm{g}} \frac{2}{d_{\mathrm{b}}} \rho_{\mathrm{l}}\left|\boldsymbol{u}_{1}-\boldsymbol{u}_{\mathrm{g}}\right|^{2} \hat{\boldsymbol{y}}
$$

The model for the wall lubrication force coefficient is according to Tomiyama (1998):

$$
C_{\mathrm{W}}=C_{\mathrm{W}, \mathrm{Eo}} \frac{d_{\mathrm{b}}}{2}\left[\frac{1}{y_{\mathrm{w}}^{2}}-\frac{1}{\left(D_{\mathrm{col}}-y_{\mathrm{w}}\right)^{2}}\right]
$$

with

$$
C_{\mathrm{W}, \mathrm{Eo}}=\left\{\begin{array}{lc}
0.47, & E o<1 \\
\exp (-0.933 E o+0.179), & 1 \leq E o \leq 5 \\
0.00599 E o-0.0187, & 5<\text { Eo } \leq 33 \\
0.179, & 33<\text { Eo }
\end{array}\right.
$$

The turbulent dispersion force is according to Burns et al. (2004):

$$
\boldsymbol{F}^{\mathrm{TD}}=-C_{\mathrm{D}} \alpha_{\mathrm{g}} \frac{3}{4 d_{\mathrm{b}}}\left|\boldsymbol{u}_{1}-\boldsymbol{u}_{\mathrm{g}}\right| \frac{\mu_{1}^{\text {turb }}}{\sigma_{\mathrm{TD}}}\left(\frac{1}{\alpha_{1}}+\frac{1}{\alpha_{\mathrm{g}}}\right) \nabla \alpha_{\mathrm{g}}
$$

with the turbulent Schmidt number $\sigma_{\mathrm{TD}}$ and typically a value of $\sigma_{\text {TD }}=0.9$ is used (Rzehak and Kriebitzsch, 2015).

The virtual mass force is

$$
\boldsymbol{F}^{\mathrm{VM}}=C_{\mathrm{VM}} \alpha_{\mathrm{g}} \rho_{1}\left(\frac{\mathrm{D} \boldsymbol{u}_{1}}{\mathrm{D} t}-\frac{\mathrm{D} \boldsymbol{u}_{\mathrm{g}}}{\mathrm{D} t}\right)
$$

with the material derivative $\mathrm{D} / \mathrm{D} t$ and the coefficient $C_{\mathrm{VM}}=0.5$ (Zhang et al., 2006).

For the solid-liquid phase interactions, the exchange terms are written in analogy to Eq. (5) as

$$
\boldsymbol{F}_{\mathrm{s}, \mathrm{l}}^{\text {inter }}=-\boldsymbol{F}_{\mathrm{l}, \mathrm{s}}^{\text {inter }}=\boldsymbol{F}_{\mathrm{p}}^{\mathrm{D}}+\boldsymbol{F}_{\mathrm{p}}^{\mathrm{VM}}
$$

For the drag coefficient, the variables are $\boldsymbol{u}_{\mathrm{g}}=\boldsymbol{u}_{\mathrm{s}}, \alpha_{\mathrm{g}}=\alpha_{\mathrm{s}}$, and $d_{\mathrm{b}}=d_{\mathrm{p}}$ in Eq. (6) and the transition of $C_{\mathrm{D}}$ is depending on $\alpha_{1}$ :

$$
C_{\mathrm{D}}= \begin{cases}\frac{24}{\operatorname{Re}}\left[1+0.15\left(\alpha_{1} R e\right)^{0.687}\right] \alpha_{1}^{-2.65}, & R e<1000 \\ 0.44 \alpha_{1}^{-1.65}, & R e \geq 1000\end{cases}
$$

for $\alpha_{1} \geq 0.8$ and

$$
C_{\mathrm{D}}=\frac{4}{3}\left(150 \frac{\alpha_{\mathrm{s}}}{\alpha_{\mathrm{l}}} \frac{v_{1}}{d_{\mathrm{p}}}\left|\boldsymbol{u}_{\mathrm{s}}-\boldsymbol{u}_{1}\right|^{-1}+1.75\right)
$$

for $\alpha_{1}<0.8$ following Gidaspow (1994).

For the solid-particle phase, the coefficient for the virtual mass force is $C_{\mathrm{vM}}=0.5$ (Ojima et al., 2014).

In conclusion, the phase interactions can be depicted schematically in Fig. 1. The schematic shows additionally where the PBE is placed in the CFD-PBE approach.

To account for turbulence and to calculate the dissipation rate of the turbulent kinetic energy $\varepsilon$ in the continuous liquid-

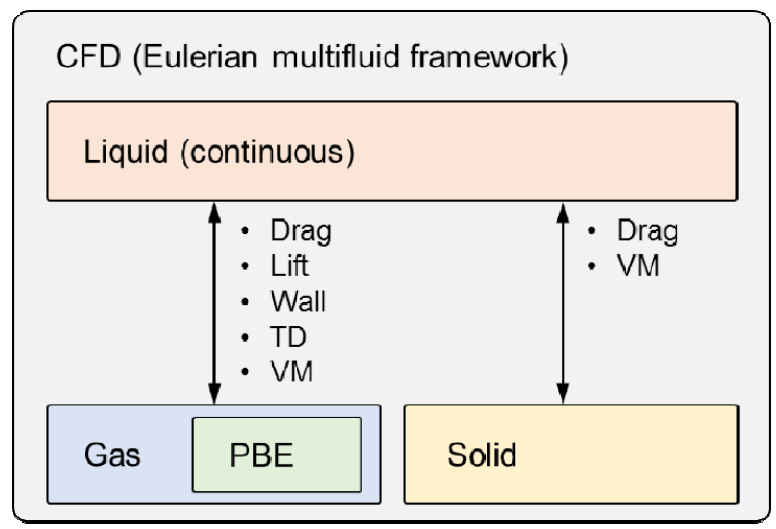

Fig. 1 Coupling of the phases within the CFD-PBE approach. 
phase, the $k-\varepsilon$ model is applied where the expressions of the $k$ and $\varepsilon$ conservation equations are

$$
\frac{\partial\left(\alpha_{1} \rho_{1} k\right)}{\partial t}+\nabla \cdot\left[\alpha_{1} \rho_{1} \boldsymbol{u}_{1} k-\alpha_{1}\left(\mu_{1}+\frac{\mu_{1}^{\text {turb }}}{\sigma_{k}}\right) \nabla k\right]=\alpha_{1}\left(G-\rho_{1} \varepsilon\right)
$$

and

$$
\begin{aligned}
& \frac{\partial\left(\alpha_{1} \rho_{1} \varepsilon\right)}{\partial t}+\nabla \cdot\left[\alpha_{1} \rho_{1} \boldsymbol{u}_{1} \varepsilon-\alpha_{1}\left(\mu_{1}+\frac{\mu_{1}^{\text {turb }}}{\sigma_{\varepsilon}}\right) \nabla \varepsilon\right] \\
= & \alpha_{1}\left(C_{\varepsilon 1} \frac{\varepsilon}{k} G-C_{\varepsilon 2} \rho_{1} \frac{\varepsilon^{2}}{k}\right)
\end{aligned}
$$

with the constants $\sigma_{k}=1.0, \sigma_{\varepsilon}=1.3, C_{\varepsilon 1}=1.44, C_{\varepsilon 2}=1.92$ and the production of turbulent kinetic energy $G=\tau_{1}: \nabla \boldsymbol{u}_{1}$. The shear-induced turbulent viscosity is modeled as

$$
\mu_{1}^{\text {turb }}=C_{\mu} \rho_{1} \frac{k^{2}}{\varepsilon}
$$

with $C_{\mu}=0.09$ (Zhang et al., 2006).

\subsection{Population balance equation}

In the closure models above, the bubble diameter $d_{\mathrm{b}}$ is an important parameter to solve the set of equations for the conservations of momentum and to calculate the velocity fields for each phase. The PBE is solved for the gas bubbles to account for changes in the BSD due to breakup and coalescence:

$$
\begin{aligned}
& \frac{\partial n(V)}{\partial t}+\nabla \cdot\left(\boldsymbol{u}_{\mathrm{g}} n(V)\right) \\
= & \int_{V}^{\infty} v_{\mathrm{b}}\left(V^{\prime}\right) \beta_{\mathrm{b}}\left(V, V^{\prime}\right) g_{\mathrm{b}}\left(V^{\prime}\right) n\left(V^{\prime}\right) \mathrm{d} V^{\prime}-g_{\mathrm{b}}(V) n(V) \\
+ & \frac{1}{2} \int_{0}^{V} \Gamma_{\mathrm{c}}\left(V-V^{\prime}, V^{\prime}\right) n\left(V-V^{\prime}\right) n\left(V^{\prime}\right) \mathrm{d} V^{\prime} \\
- & n(V) \int_{0}^{\infty} \Gamma_{\mathrm{c}}\left(V, V^{\prime}\right) n\left(V^{\prime}\right) \mathrm{d} V^{\prime}
\end{aligned}
$$

Eq. (29) is the volume-based formulation of the PBE for the number density function $n$ of bubble volume $V$. The coalescence frequency can be further split up into two terms for coalescence of two bubbles with volumes $V$ and $V^{\prime}$ :

$$
\Gamma_{\mathrm{c}}\left(V, V^{\prime}\right)=\lambda_{\mathrm{c}}\left(V, V^{\prime}\right) h_{\mathrm{c}}\left(V, V^{\prime}\right)
$$

The source terms in the PBE on the right-hand side account for birth and death due to breakage and coalescence of bubbles, respectively. Breakup and coalescence mainly depend on the fluid properties and flow conditions.

The applied models for the breakage frequency $g_{\mathrm{b}}$ and the daughter size distribution $\beta_{b}$ for the formation of $a$ bubble with volume $V$ from breakage of a bubble with volume
$V^{\prime}$ (Laakkonen et al., 2006, 2007) are

$$
g_{\mathrm{b}}=C_{\mathrm{L} 1} \varepsilon^{\frac{1}{3}} \operatorname{erfc}\left(\left(C_{\mathrm{L} 2} \frac{\sigma}{\rho_{1} \varepsilon^{\frac{2}{3}} d_{\mathrm{b}}^{\frac{5}{3}}}+C_{\mathrm{L} 3} \frac{\mu_{1}}{\left(\rho_{1} \rho_{\mathrm{g}}\right)^{\frac{1}{2}} \varepsilon^{\frac{1}{3}} d_{\mathrm{b}}^{\frac{4}{3}}}\right)^{\frac{1}{2}}\right)
$$

and

$$
\begin{aligned}
\beta_{\mathrm{b}}= & \frac{1}{2}\left(1+C_{\mathrm{L} 4}\right)\left(2+C_{\mathrm{L} 4}\right)\left(3+C_{\mathrm{L} 4}\right)\left(4+C_{\mathrm{L} 4}\right) \\
& \cdot\left(\frac{d_{\mathrm{b} i}^{2}}{d_{\mathrm{b} j}^{3}}\right)\left(\frac{d_{\mathrm{b} i}^{3}}{d_{\mathrm{b} j}^{3}}\right)^{2}\left(1-\frac{d_{\mathrm{b} i}^{3}}{d_{\mathrm{b} j}^{3}}\right)^{C_{L 4}}
\end{aligned}
$$

with the constants $C_{\mathrm{L} 1}=2.52, C_{\mathrm{L} 2}=0.04, C_{\mathrm{L} 3}=0.01$, and $C_{\mathrm{L} 4}=2$. The number of daughter bubbles is $v_{\mathrm{b}}=2$.

The coalescence model of Prince and Blanch (1990) was applied for the collision frequency $h_{c}$ to account for turbulent and buoyancy-driven collision of bubbles:

$$
\begin{aligned}
h_{\mathrm{c}}= & C_{\mathrm{P} 1} \pi \varepsilon^{\frac{1}{3}}\left(d_{\mathrm{b} i}+d_{\mathrm{b} j}\right)^{2}\left(d_{\mathrm{b} i}^{\frac{2}{3}}+d_{\mathrm{b} j}^{\frac{2}{3}}\right)^{\frac{1}{2}} \\
& +0.25 \pi\left(d_{\mathrm{b} i}+d_{\mathrm{b} j}\right)^{2}\left|u_{\mathrm{b} i}-u_{\mathrm{b} j}\right|
\end{aligned}
$$

with $C_{\mathrm{P} 1}=0.089$ and the expression for the rise velocity of a bubble:

$$
u_{\mathrm{b}}=\left(\frac{2.14 \sigma}{\rho_{\mathrm{l}} d_{\mathrm{b}}}+0.505 g d_{\mathrm{b}}\right)^{\frac{1}{2}}
$$

The general approach for the coalescence efficiency is

$$
\lambda_{\mathrm{c}}=\exp \left(-\frac{t_{i j}}{\tau_{i j}}\right)
$$

with the film drainage time $t_{i j}$ and the bubble contact time $\tau_{i j}$ and is calculated following Prince and Blanch (1990):

$$
\lambda_{\mathrm{c}}=\exp \left(-\frac{r_{\mathrm{bij}}^{\frac{5}{6}} \rho_{\mathrm{l}}^{\frac{1}{2}} \varepsilon^{\frac{1}{3}}}{4 \sigma^{\frac{1}{2}}} \ln \left(\frac{h_{0}}{h_{\mathrm{f}}}\right)\right)
$$

with the equivalent radius

$$
r_{\mathrm{b} i j}=\left(\frac{1}{d_{\mathrm{b} i}}+\frac{1}{d_{\mathrm{bj}}}\right)^{-1}
$$

of two coalescing bubbles, the initial film thickness $h_{0}=10^{-4} \mathrm{~m}$, and the critical film thickness $h_{\mathrm{f}}=10^{-8} \mathrm{~m}$.

\section{Modeling of solid-particle effects}

The development of the modeling of bubble breakage and coalescence within the coupled CFD-PBE approach has been advancing since about two decades. Substantial progress was made but today there are still limitations when one wants to consider different material systems than 
the commonly studied academic systems (Wang, 2011). An example is given by the presence of solid particles in dispersed gas-liquid-solid systems. The effects of solid particles on bubble breakage and coalescence mentioned in Section 1 are missing in the models presented in Section 2.2 as they are solely derived for two-phase flow. The coalescence enhancing effect of microparticles is of special interest within this work. Up to now, the following approaches to modify the models can be found in literature to account for the effect:

A) Breakup/coalescence parameter adaption (COPAA);

B) Introduction of a solid-effect multiplier (SEM);

C) Modification/scaling of the turbulent kinetic energy dissipation rate $\varepsilon$ (SCEPS).

The approaches aim at different sub-models in breakage and coalescence modeling. An overview is given in Fig. 2. The three approaches are explained in detail in the subsequent sections.

\subsection{Coalescence parameter adaption (COPAA)}

With this approach, the parameters (i.e., constants) of the breakup and/or coalescence models are adjusted to satisfy a certain condition and fit simulation with experimental target quantities. In many cases, the comparative quantity is the total gas holdup ( $\mathrm{Xu}$ et al., 2014). Its value is easy measurable also in more complex material systems. However, to validate a model for a system where the phenomena are strongly coupled, more quantities should be considered also at different spatial positions. For example, Schäfer et al. (2019) adjusted parameters to fit simulated with measured bubble diameters for 18 spatial positions in a bubble column. In general, an adequate experimental data base must be available to adapt the model parameters.

For the simulations, the coalescence parameter $C_{\mathrm{P} 1}=C_{\mathrm{P} 1, \text { adapt }}$ in Eq. (33) of the Prince and Blanch coalescence

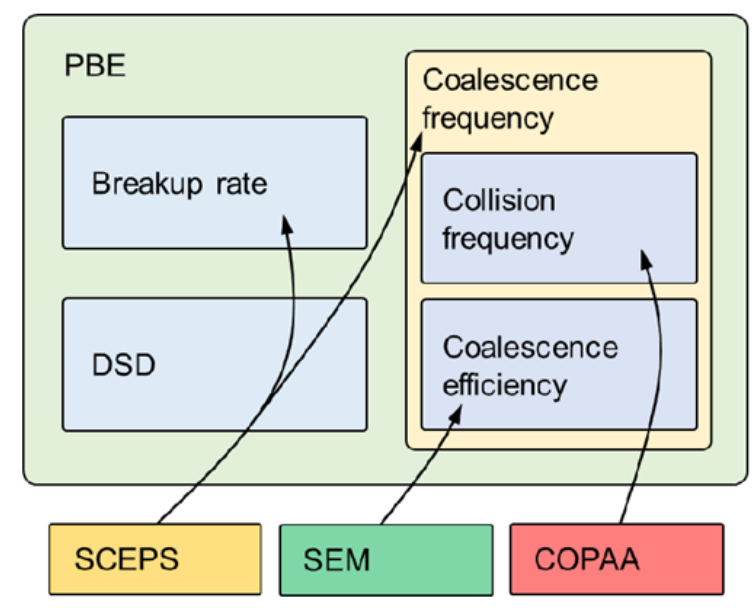

Fig. 2 Overview over the applied approaches in the breakup and coalescence models. model was adjusted, i.e., the collision frequency is modified (c.f., Fig. 2). The parameter adaption can be regarded as a coarse parameter variation with $C_{\mathrm{P} 1 \text {,adapt }}=a \times C_{\mathrm{P} 1}$ and $a=1,2,3, \ldots$ due to expensive numerics. The simulation results are compared with experimental data to check on agreement and thus to determine $C_{\mathrm{P} 1 \text {,adapt }}$ for every operating point.

\subsection{Solid-effect multiplier (SEM)}

A solid-effect multiplier $\beta$ is introduced to the expression of the coalescence efficiency (Ojima et al., 2014; Sarhan et al., 2018):

$$
\lambda_{\mathrm{c}}=\exp \left(-\frac{\beta t_{i j}}{\tau_{i j}}\right)
$$

where $\beta$ may have values between 0 and 1 and can be derived from film rupture measurement of two coalescing bubbles. The following correlation was derived for the considered $\mathrm{SiO}_{2}$ particles with a diameter of $d_{\mathrm{p}}=100 \mu \mathrm{m}$ (Ojima et al., 2015):

$$
\beta=\left\{\begin{array}{lr}
\left(-10.6 \alpha_{\mathrm{s}}^{3}+5.72 \alpha_{\mathrm{s}}^{2}+1\right)\left[\frac{1}{2} \cos \left(\frac{20 \pi}{9} \alpha_{\mathrm{s}}\right)+\frac{1}{2}\right], \alpha_{\mathrm{s}}<0.45 \\
0, & \alpha_{\mathrm{s}} \geq 0.45
\end{array}\right.
$$

Varying coefficients for the polynomial function in Eq. (39) can be found for different particle diameters. The correlations were deduced from coalescence time measurements, which were analyzed with high-speed camera recordings in a quasi-2D bubble column, and yet the applicability of the correlations in numerical simulations was shown (Ojima et al., 2015).

\subsection{Scaling of $\varepsilon$ (SCEPS)}

The third approach is derived from results based on direct numerical simulations (DNS). It was found that the dissipation rate of turbulent kinetic energy $\varepsilon$ is attenuated in simulations of dilute suspensions (Squires and Eaton, 1994). Troshko and Zdravistch (2009) scaled the dissipation rate with an attenuation factor as an exponential function of the solid-particle volume fraction. They based their scaling approach on DNS data from Squires and Eaton (1994), which is available for varied particle loadings and particle Stokes numbers $S t$ and found:

$$
\frac{\varepsilon}{\varepsilon_{0}}=\exp \left(-C_{\varepsilon} \alpha_{\mathrm{s}}\right)
$$

with $C_{\varepsilon}=1.2846$ for $S t=0.25$. However, they mention that $C_{\varepsilon}$ has to be increased by a value of 10 to obtain agreement between experimental and simulation data.

St can be estimated with the Kolmogorov time scale $\tau_{1}=\sqrt{v_{1} / \varepsilon}$ (Sundaram and Collins, 1999): 


$$
S t=\frac{\tau_{\mathrm{p}}}{\tau_{1}}=\frac{\rho_{\mathrm{p}} d_{\mathrm{p}}^{2}}{18 \mu_{1}} \sqrt{\frac{\varepsilon}{v_{1}}}
$$

The dissipation rate $\varepsilon$ in bubble columns can be approximated as

$$
\varepsilon=U_{\mathrm{g}} g
$$

with the assumption that all energy is dissipated in the liquid-phase and the absence of stagnant regions (Baird and Rice, 1975). The particle Stokes number in the investigated case is approximately 0.6 and is within the same order of magnitude $<1.0$ as found in the work of Troshko and Zdravistch (2009). Therefore, the increased value of $C_{\varepsilon}=11.3$ was used also in this work.

SCEPS is applied for the calculation of the PBE only, i.e., it affects the models for the breakup rate and the coalescence frequency as indicated in Fig. 2 but not the multifluid equations given in Section 2.1.

\section{Simulation}

A literature test case is considered comparing and validating the simulation results obtained in this work with experimental data (Ojima et al., 2014). In the following sections, the simulation case as well as the numerical methods is described.

\subsection{Simulation case description}

The examined slurry bubble column has a height of $1.2 \mathrm{~m}$ and a square cross section with an edge length of $0.2 \mathrm{~m}$. The column was filled with purified water and equally distributed spherical silica particles $\left(\mathrm{SiO}_{2}\right)$ up to an initial filling height of $0.8 \mathrm{~m}$. The column was gassed with air via 49 equally distributed needles over the bottom of the column. The experiments were carried out at normal temperature and pressure $\left(20^{\circ} \mathrm{C}, 1.0 \mathrm{bar}\right)$. The superficial gas velocities were 0.020 and $0.034 \mathrm{~m} / \mathrm{s}$. The initial bubble diameters were calculated to be 10 and $13 \mathrm{~mm}$, respectively, according to the Davidson-Schüler correlation (Davidson and Schüler, 1960). Monodisperse solid particles were assumed and the height of the 3D simulation domain was chosen to be $1.0 \mathrm{~m}$ in accordance with the simulations of Ojima et al. (2014). The gas inlet and outlet were represented by the bottom and the top of the column, respectively. The slip condition was applied for the disperse gas and solid-particle phase at the column walls and the no-slip condition for the liquid-phase. All properties of the domain, the gas, liquid, and solid-particle phases as well as the boundary conditions are summarized in Table 1.

For comparison with experimental data, local gas volume fractions are available for 13 measurement points equally spaced on a line across the column width through the center of the column at a height of $0.6 \mathrm{~m}$ above the bottom
Table 1 Phase properties and boundary conditions in the simulations

\begin{tabular}{llll}
\hline \multirow{4}{*}{ Domain } & Width $\times$ depth $\times$ height $(\mathrm{m})$ & $0.2 \times 0.2 \times 1.0$ \\
& Hydraulic diameter $D_{\text {col }}(\mathrm{m})$ & 0.2 & \\
& Filling height $H_{0}(\mathrm{~m})$ & 0.8 & \\
\hline \multirow{4}{*}{ Gas-phase } & Superficial gas velocity $U_{\mathrm{g}}(\mathrm{m} / \mathrm{s})$ & 0.020 & 0.034 \\
& Initial bubble diameter $d_{\mathrm{b}}(\mathrm{mm})$ & 11 & 13 \\
& Density $\rho_{\mathrm{g}}\left(\mathrm{kg} / \mathrm{m}^{3}\right)$ & 1.2 & \\
& Viscosity $\mu_{\mathrm{g}}(\mathrm{mPa} \cdot \mathrm{s})$ & 0.0182 \\
\hline \multirow{3}{*}{ Liquid-phase } & Density $\rho_{\mathrm{l}}\left(\mathrm{kg} / \mathrm{m}^{3}\right)$ & 998 \\
& Viscosity $\mu_{1}(\mathrm{mPa} \cdot \mathrm{s})$ & 1.00 \\
& Surface tension $\sigma(\mathrm{N} / \mathrm{m})$ & 0.0728 \\
\hline \multirow{2}{*}{ Solid-particle } & Particle diameter $d_{\mathrm{p}}(\mu \mathrm{m})$ & 100 \\
phase & Density $\rho_{\mathrm{s}}\left(\mathrm{kg} / \mathrm{m}^{3}\right)$ & 2250 \\
& Volumetric concentration $c_{\mathrm{s}}(\mathrm{vol} \%)$ & $0,20,40$ \\
\hline
\end{tabular}

of the column (Ojima et al., 2014). The experimental data was obtained with an electric conductivity needle probe. The measurement time was $900 \mathrm{~s}$ for each single measurement point to analyze and average the local gas holdup. The data is available for all considered superficial gas velocities and solid-particle concentrations.

\subsection{Numerical methods}

The simulations were carried out with the open source CFD code OpenFOAM v6 (Weller et al., 2018). In particular, the reactingEulerFoam solver was used, which is part of OpenFOAM since v3.0.0 in 2015. The solver has the capabilities to simulate two-phase and in general multiphase flows coupled with reactive heat and mass transfer. It is still evolving rapidly due to contributions of multiphase flow research institutes such as the Technical Research Centre of Finland VTT and Helmholtz-Zentrum Dresden-Rossendorf (HZDR).

The conservation equations of mass and momentum Eqs. (1) and (2) as well as the turbulence quantities Eqs. (26) and (27) were discretized spatially with the finite volume method (FVM). The domain was discretized with different resolutions of cubic cells to ensure grid independency. Specifications of the investigated grids can be found in Table 2. The results of the simulated gas holdups along the center line ( $x$ direction) in the column, where all results in this work will be analyzed, are depicted in Fig. 3 for $U_{\mathrm{g}}=$ $0.034 \mathrm{~m} / \mathrm{s}$ and $c_{\mathrm{s}}=20 \mathrm{vol} \%$.

Table 2 Investigated spatial discretizations of the domain with cubic cells

\begin{tabular}{ccc}
\hline Grid & No. of cells & Cell edge length $(\mathrm{m})$ \\
\hline 1 & 16,875 & $13.33 \times 10^{-3}$ \\
2 & 40,000 & $10 \times 10^{-3}$ \\
3 & 78,125 & $8 \times 10^{-3}$ \\
\hline
\end{tabular}




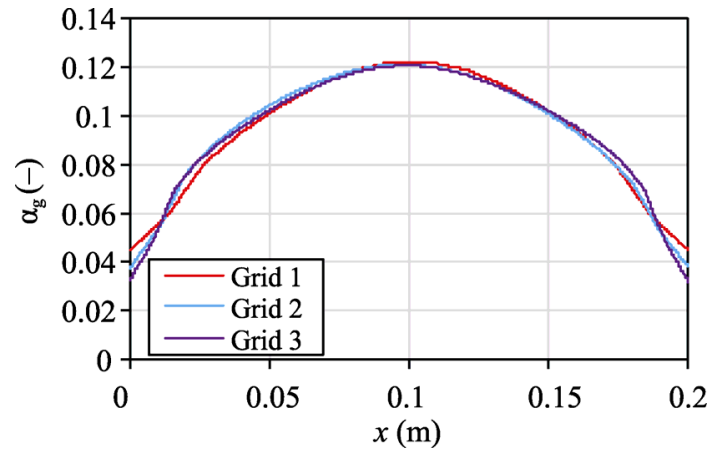

Fig. 3 Simulated gas holdup profiles with different spatial discretizations.

The simulated gas holdup profiles match well across the whole column width and especially at the column walls for grids 2 and 3. The mean relative error between these grids is $2.2 \%$. Therefore, grid 2 was chosen to discretize the domain. The time step was $1 \mathrm{~ms}$ and the duration of one simulation was $230 \mathrm{~s}$ where the last $200 \mathrm{~s}$ were averaged over time with an interim result every $0.5 \mathrm{~s}$. The gas holdup and velocity profiles as well as BSD and the representative Sauter mean diameters were evaluated.

Eq. (29) was discretized and solved numerically with the homogeneous classes method (CM) (Hounslow et al., 1988; Chen et al., 2004). The bubble diameter class centers were ranging from 3.3 to $57 \mathrm{~mm}$ and were split into 22 classes. The diameter of the larger class $i+1$ was always the diameter with a sphere equivalent volume $V_{i+1}=1.5 \times V_{i}$ larger than the equivalent volume of the smaller class $i$.

The Sauter mean diameter was calculated as the harmonic mean (Chen et al., 2008):

$$
d_{32}=\left(\sum_{i=1}^{N} \frac{f_{i}}{d_{b, i}}\right)^{-1}
$$

with the volume fraction $f_{i}$ of all bubbles in one class $i$ with respect to the total volume of all bubbles in all classes.

The locally calculated Sauter mean diameter representing the BSD was applied in the models for the gas-liquid interphase exchange terms in Eq. (5).

\section{Results and discussion}

The presented approaches (COPAA, SEM, SCEPS) are applied and the outcomes are compared with simulation data without special consideration of microparticle effects, i.e., no modification of the breakup and coalescence models (NOMOD) as well as with experimental data. The results are shown on the center line along the column width in $x$ direction at a height $h=0.6 \mathrm{~m}$ above the gas distributor.

\subsection{Gas holdup and bubble velocity}

In Fig. 4, the measured and calculated gas holdup profiles are depicted across the column width for both superficial gas velocities $U_{\mathrm{g}}=0.020$ and $0.034 \mathrm{~m} / \mathrm{s}$ (left and right) and the solid-particle concentrations $c_{\mathrm{s}}=0,20$, and $40 \mathrm{vol} \%$ (from top to bottom).

The simulated time averaged gas holdup profiles for the absence of solid particles agree well with the measured profiles of Ojima et al. (2014), especially in the outer regions near the column wall. In the core of the column, the simulated gas holdups underestimate the measured values. This might be affected by the assumption of monodisperse bubbles at the column inlet following Ojima et al. (2014), which leads to a more uniform gas volume fraction distribution than with a broader BSD (see also Section 5.2). It can be confirmed when looking at the gas holdup profiles, which turn steeper for the modified breakup and coalescence models with the presence of solid particles.

The boundary conditions and the applied models, especially for breakup and coalescence seem to be appropriate for simulating the considered case. They depict the trends correctly and the simulation results are close to the measured values for all solid-particle concentrations $c_{\mathrm{s}}$ and superficial gas velocities $U_{\mathrm{g}}$.

All breakup and coalescence modification approaches with the presence of solid particles show the same trend and improve the simulation results in a similar manner. The local gas holdup results are lowered for all three approaches (COPAA, SEM, SCEPS) and the simulated profiles agree better with the measured profiles. It can be seen that with $c_{\mathrm{s}}=20 \mathrm{vol} \%$, all three modification approaches result in nearly the same gas holdup profiles, whereas with $c_{\mathrm{s}}=40$ $\mathrm{vol} \%$, the profiles begin to differ. For $c_{\mathrm{s}}=40 \mathrm{vol} \%$ and $U_{\mathrm{g}}=$ $0.020 \mathrm{~m} / \mathrm{s}$, SCEPS overestimates and for $c_{\mathrm{s}}=40 \mathrm{vol} \%$ and $U_{\mathrm{g}}=$ $0.034 \mathrm{~m} / \mathrm{s}, \mathrm{SEM}$ underestimates the gas holdup. The reasons are analyzed in Section 5.2.

For the investigated case, no experimental data for the velocities was reported. The simulated absolute bubble velocities $u_{\mathrm{b}}$, which correspond to the absolute gas-phase velocities $\left|\boldsymbol{u}_{\mathrm{g}}\right|$ in the Eulerian multifluid approach, are shown in Fig. 5.

When comparing Fig. 5 with Fig. 4, the strong coupling between the velocity and the gas holdup profiles in bubble columns becomes obvious. Though, the relative deviations are slightly higher for the velocity profiles between the applied modification approaches with respect to the differing gas holdup profiles. For $c_{\mathrm{s}}=40 \mathrm{vol} \%$ and $U_{\mathrm{g}}=$ $0.034 \mathrm{~m} / \mathrm{s}$, the time averaged absolute bubble velocity profiles become slightly asymmetric. This can be corrected with time averaging over longer time intervals. However, it also shows that the bubble plume oscillations and therefore the whole dynamics in the system are affected, when the models for breakup and coalescence are modified.

The simulated bubble and liquid velocities $u_{\mathrm{b}}$ and $u_{1}$ are 

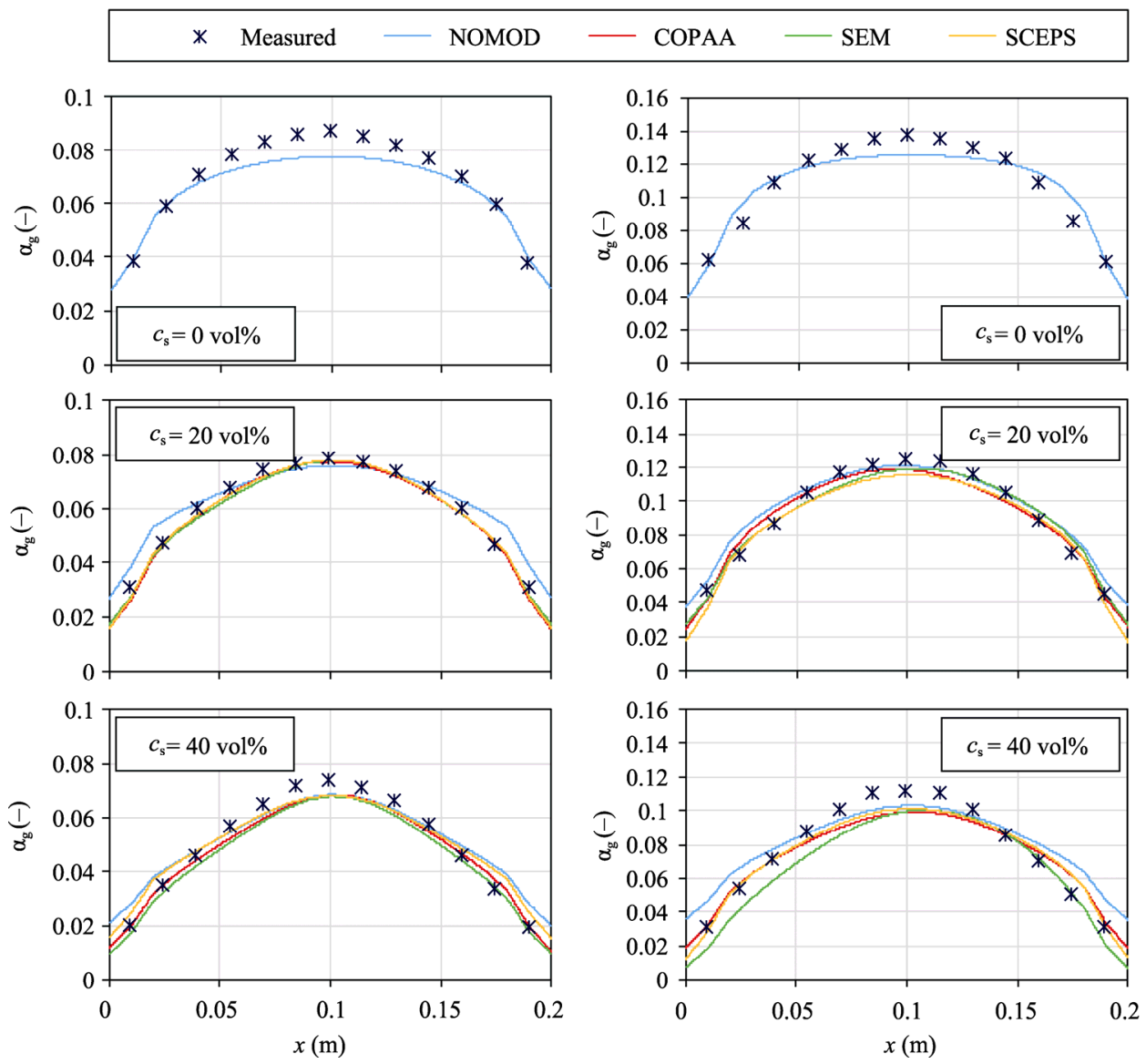

Fig. 4 Gas holdup profiles for $U_{\mathrm{g}}=0.020 \mathrm{~m} / \mathrm{s}$ (left) and $U_{\mathrm{g}}=0.034 \mathrm{~m} / \mathrm{s}$ (right).

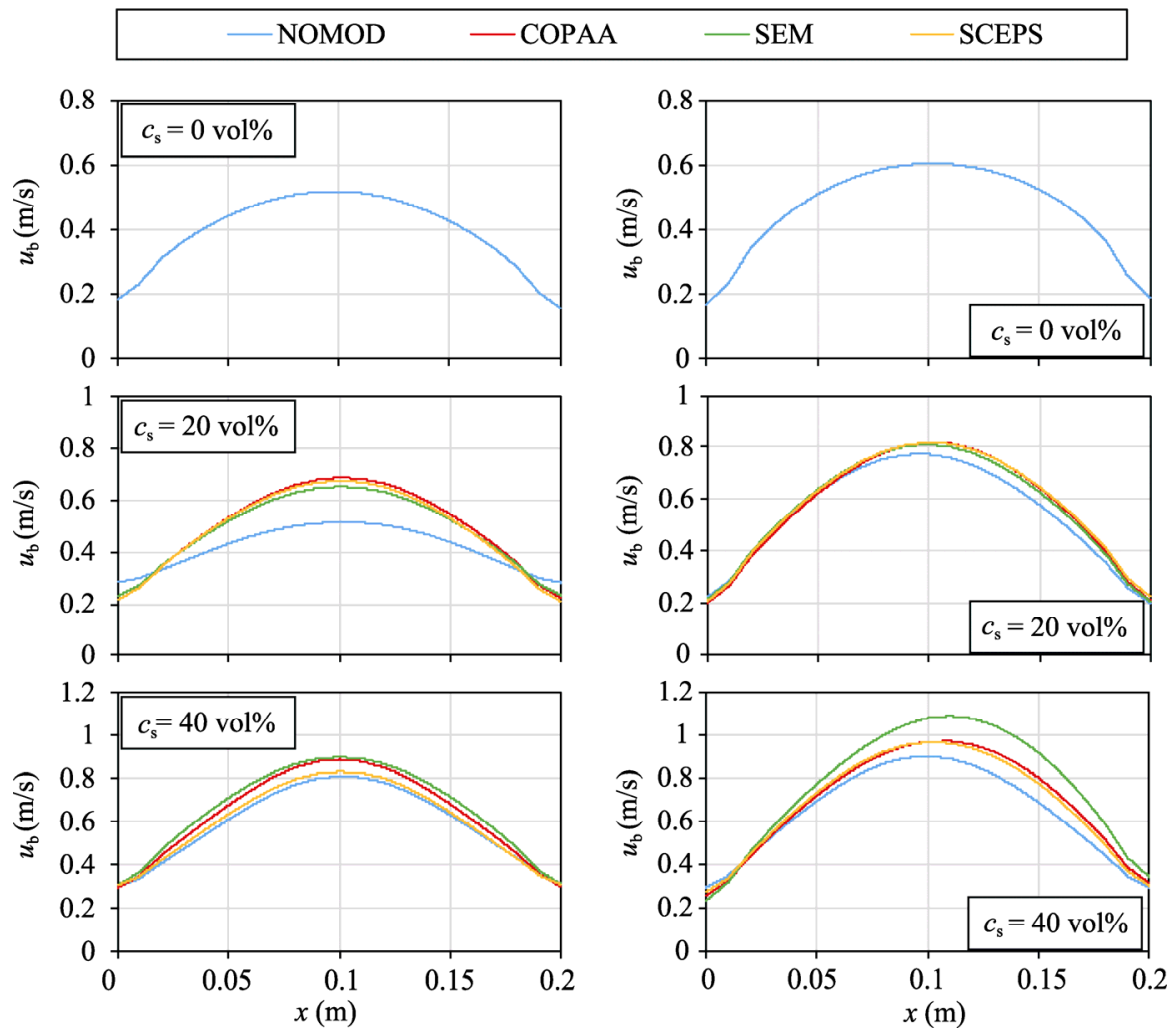

Fig. 5 Simulated absolute bubble velocity profiles for $U_{\mathrm{g}}=0.020 \mathrm{~m} / \mathrm{s}$ (left) and $U_{\mathrm{g}}=0.034 \mathrm{~m} / \mathrm{s}$ (right). 
plotted in Fig. 6 for comparison with available simulation results of Ojima et al. (2014).

In general, a similar trend can be seen in both the simulation results of Ojima et al. (2014) and this work, where the enhanced coalescence of bubbles leads to an increase of $u_{\mathrm{b}}$. The results of $u_{1}$ are in good agreement and the velocities at higher solid-particle concentrations increased likewise. At the column walls the liquid velocities deviate because of the applied slip condition of Ojima et al. (2014). The bubble velocities calculated in this work are higher than the values obtained by Ojima et al. (2014). The differences might arise due to Ojima et al. (2014) accounting for an apparent viscosity of the slurry when calculating the gas-liquid drag. However, there also can be found other published simulations of the investigated case without consideration of viscous effects of the solid particles on the drag force (Sarhan et al., 2018). Further experimental data is required to validate the velocity profiles.

The link between the bubble velocity and the local gas holdup is the bubble diameter. The Sauter mean diameter $d_{32}$ was used to represent the mean bubble diameter of the whole BSD according to Eq. (43) in the closure models written in Eq. (5). Special consideration of these quantities can be found in the following section.

\subsection{Bubble size distribution}

The calculated bubble volume density distribution functions $q_{3}$ are plotted in Fig. 7. The time averaged sample along the center line through the column at a height of $h=0.6$ $\mathrm{m}$ above the gas distributor (c.f., Fig. 4 and Fig. 5) was used for analysis.

In all distributions, the monodisperse inlet conditions of $d_{\mathrm{b}}=11 \mathrm{~mm}$ and $d_{\mathrm{b}}=13 \mathrm{~mm}$ can be still recognized for $U_{\mathrm{g}}=0.020 \mathrm{~m} / \mathrm{s}$ and $U_{\mathrm{g}}=0.034 \mathrm{~m} / \mathrm{s}$, respectively. When no

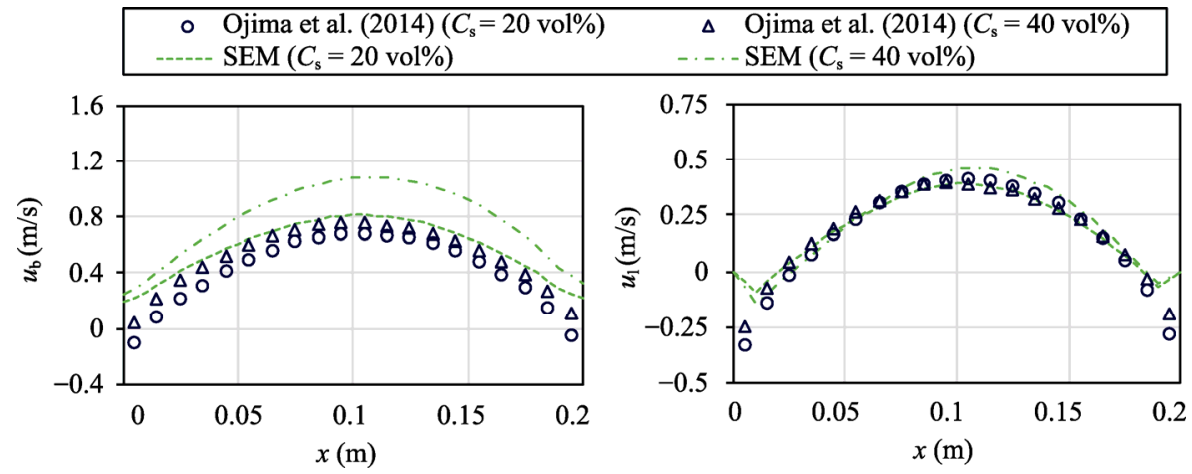

Fig. 6 Comparison of simulated bubble (left) and liquid velocities (right) for $U_{\mathrm{g}}=0.034 \mathrm{~m} / \mathrm{s}$.
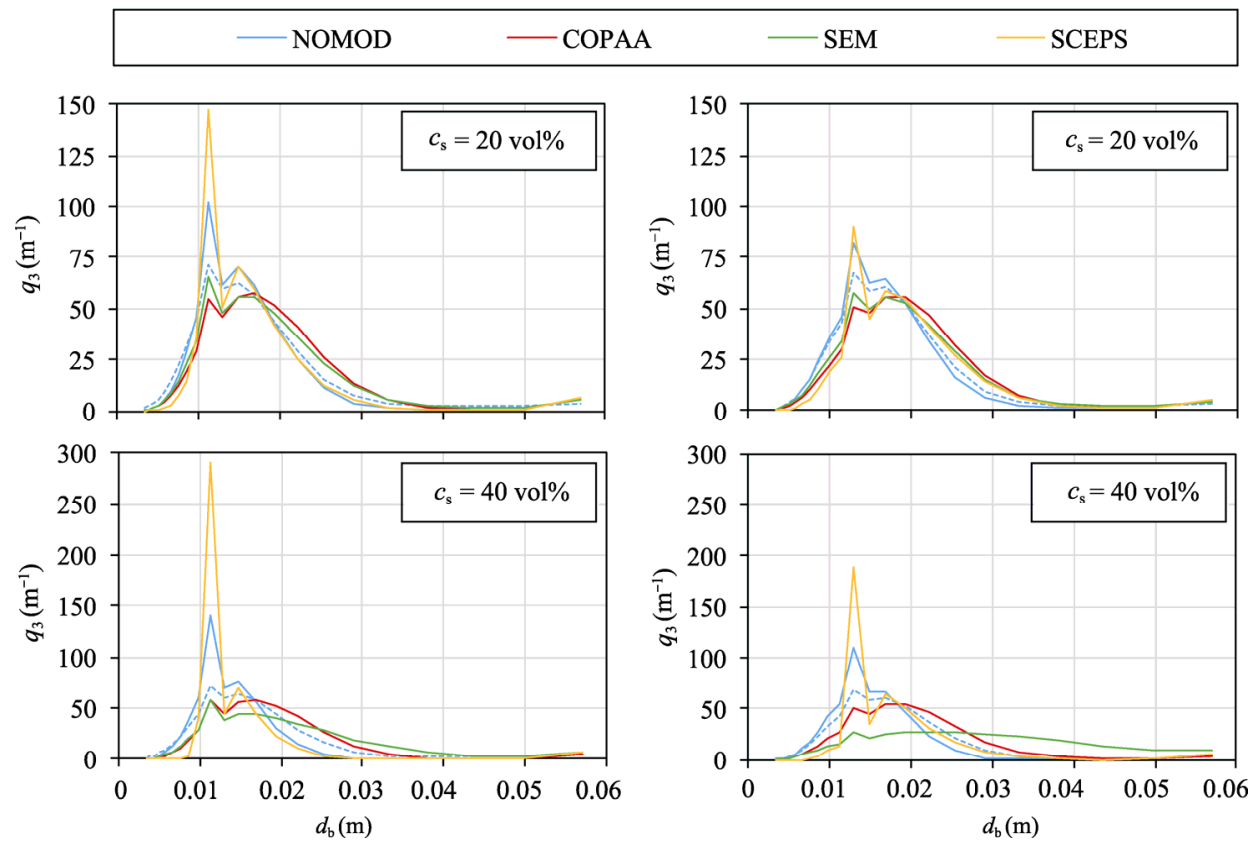

Fig. 7 Simulated volumetric bubble size distributions with respective reference results for $c_{\mathrm{s}}=0$ vol\% (dashed line) for $U_{\mathrm{g}}=0.020 \mathrm{~m} / \mathrm{s}$ (left) and $U_{\mathrm{g}}=0.034 \mathrm{~m} / \mathrm{s}$ (right). 
modification approaches are applied, the size distributions become narrower with the presence of solid particles (comparison of blue graphs with blue dashed graphs in Fig. 7), whereas the modification approaches COPAA and SEM lead to a broader BSD. This is due to solely increasing the collision frequency and the coalescence efficiency, respectively. The calculated $q_{3}$ distribution functions for the COPAA and SEM approach are very similar for $c_{\mathrm{s}}=$ $20 \mathrm{vol} \%$. For $c_{\mathrm{s}}=40 \mathrm{vol} \%$ the size distributions for these two approaches begin to differ and the distribution gets broader for SEM. When evaluating the results of the SCEPS approach, the major influences are the reduction of breakup with increasing $c_{\mathrm{s}}$ from 20 to $40 \mathrm{vol} \%$ and the promotion of coalescence when increasing $U_{\mathrm{g}}$ from 0.020 to $0.034 \mathrm{~m} / \mathrm{s}$.

To get a clearer idea about the trends with increasing $c_{s}$, the calculated Sauter mean diameters $d_{32}$ are depicted in Fig. 8 for both superficial gas velocities $U_{g}$. The Sauter mean diameters were calculated from the data shown in Fig. 7.

For $c_{\mathrm{s}}=0 \mathrm{vol} \%$, the Sauter mean diameter for all approaches is identical and no modification approach applies. Without any modification approach (NOMOD), the Sauter mean diameters trend to decrease with increasing $c_{\mathrm{s}}$, which is the mere hydrodynamic effect of the solid particles on breakup and coalescence in the coupled CFD-PBE approach. With COPAA and SEM, $d_{32}$ is monotonically increasing with $c_{\mathrm{s}}$ but with different characteristics. COPAA is similar to a form of a saturation function for the mean diameter, whereas SEM leads to a disproportionate increase. The trends of the SCEPS approach are similar to the NOMOD results with an elevation of $d_{32}$. However, the simulated gas holdup with SCEPS deviates from the measurements for $c_{\mathrm{s}}=40 \mathrm{vol} \%$ and $U_{\mathrm{g}}=0.020 \mathrm{~m} / \mathrm{s}$ (c.f., Fig. 4). Presumably, the most likely $d_{32}$ trend is depicted by the COPAA approach because the approach tries to replicate the experiments. Therefore, it is in general not possible to predict or extrapolate results and the approach has to be calibrated for different systems.

The calculated Sauter mean diameter fields in the $x-h$ plane in the center of the column where all other results have been shown at $h=0.6 \mathrm{~m}$ are displayed in Fig. 9 .

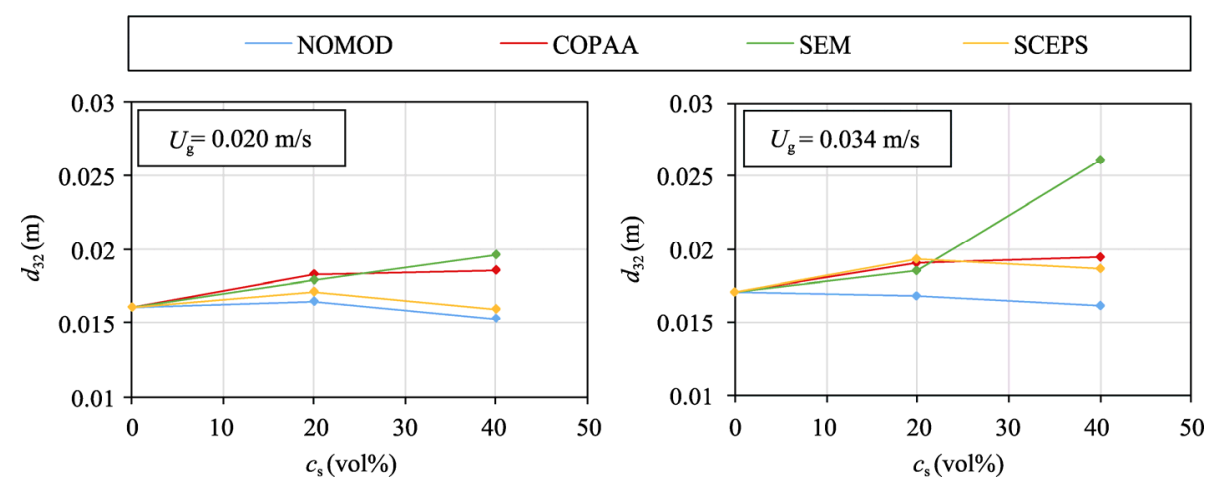

Fig. 8 Calculated Sauter mean diameters for the time averaged samples along $x$ in the column center at $h=0.6 \mathrm{~m}$.

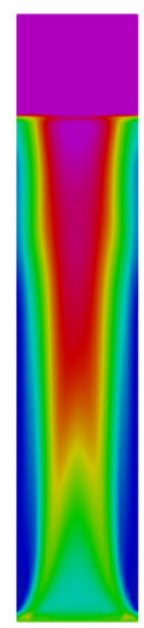

NOMOD

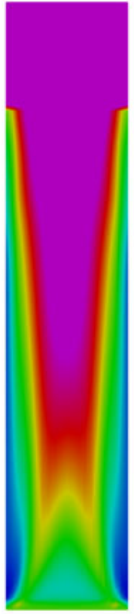

COPAA

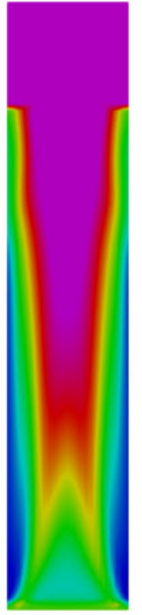

SEM

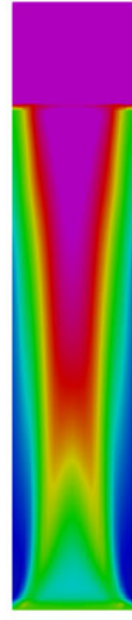

SCEPS
Sauter mean

diameter $(\mathrm{m})$

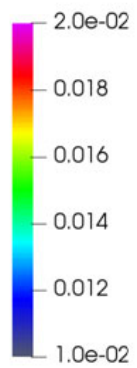

$-1.0 \mathrm{e}-02$

Fig. 9 Time averaged Sauter mean diameter fields for $c_{\mathrm{s}}=20 \mathrm{vol} \%$ and $U_{\mathrm{g}}=0.020 \mathrm{~m} / \mathrm{s}(x-h$ plane $)$. 
The promotion of coalescence is clearly visible with the modification approaches (COPAA, SEM, SCEPS). The Sauter mean diameter fields are displayed for $c_{\mathrm{s}}=20 \mathrm{vol} \%$ and $U_{\mathrm{g}}=0.020 \mathrm{~m} / \mathrm{s}$ where the gas holdup profiles hardly differ. Nevertheless, different characteristics of the coalescent core flow (green to purple) and the non-coalescent boundary regions (blue) can be detected. It gives rise to the conclusion that more than one axial measurement position would be desirable for validating breakup and coalescence models.

To get a better understanding of the effects on the breakup and coalescence models, they are visualized in Fig. 10. The following parameters were used for the calculations: The COPAA simulations resulted in the adapted coalescence parameters $C_{\mathrm{P}_{1} \text {,adapt }}\left(c_{\mathrm{s}}=20 \mathrm{vol} \%\right)=2 \times C_{\mathrm{p} 1}$ and $C_{\mathrm{P} 1, \text { adapt }}\left(c_{\mathrm{s}}=40 \mathrm{vol} \%\right)=3 \times C_{\mathrm{P} 1}$. In the SCEPS approach, the value of the parameter was $C_{\varepsilon}=11.3$. All other material properties were used as indicated in Table 1 and the dissipation rate of the turbulent kinetic energy was estimated for $U_{\mathrm{g}}=0.020 \mathrm{~m} / \mathrm{s}$ according to Eq. (42) as to $\varepsilon$ $=0.2 \mathrm{~W} / \mathrm{kg}$. For the visualization, it was further assumed that only two bubbles of the same size coalesce.

The coalescence efficiency $\lambda_{c}$ and the collision frequency $h_{c}$ are displayed at the top row of Fig. 10. The product of $\lambda_{c}$ and $h_{c}$ according to Eq. (30) leads to the coalescence frequency $\Gamma_{c}$. On the opposite side at the bottom row of Fig. 10, the breakup rate $g_{\mathrm{b}}$ is depicted.

In the default models (NOMOD), $\Gamma_{c}$ reaches a maximum at a certain bubble diameter $d_{\mathrm{b}}$ and is approaching zero again for large bubble diameters. This maximum is raised and/or shifted to larger bubble diameters with the modification approaches (COPAA, SEM, SCEPS). COPAA increases only $h_{c}$ and SEM enhances only $\lambda_{c}$, whereas SCEPS modifies both terms and in addition also $g_{\mathrm{b}}$. It is noticeable that an increasing $\lambda_{\mathrm{c}}$ results in a strong effect on $\Gamma_{c}$, especially for large bubbles and in the case of the SEM approach with high solidparticle concentrations $c_{\mathrm{s}}$ also for smaller bubbles. Due to the fine interplay of $g_{b}$ and $\Gamma_{c}$ in the PBE, mean diameters in the range as depicted in Fig. 9 occur. Further insights can be gained when the bubble diameter range $d_{\mathrm{b}}=0.01, \ldots$, $0.02 \mathrm{~m}$ is considered in Fig. 10. For the SEM approach and $c_{\mathrm{s}}=40 \mathrm{vol} \%, \Gamma_{\mathrm{c}}$ is strongly increasing and is probably overestimated. Therefore, the gas holdup in Fig. 4 is underestimated. For the SCEPS approach, the values of $\Gamma_{c}$ are lower for $d_{\mathrm{b}}<0.017 \mathrm{~m}$ for $c_{\mathrm{s}}=40 \mathrm{vol} \%$ in comparison with $c_{\mathrm{s}}=20 \mathrm{vol} \%$. Therefore, the values of $\Gamma_{\mathrm{c}}$ are too low for $c_{\mathrm{s}}=40 \mathrm{vol} \%$. Finally, the effect in the simulation is visible in Fig. 8 for $U_{\mathrm{g}}=0.020 \mathrm{~m} / \mathrm{s}$ : The Sauter mean diameter for $c_{\mathrm{s}}=40 \mathrm{vol} \%$ is smaller than for $c_{\mathrm{s}}=40 \mathrm{vol} \%$ and the gas holdup is slightly overestimated (c.f., Fig. 4).

\section{Conclusions}

Three different modification approaches for bubble breakup and coalescence models to account for enhanced coalescence due to solid-particle effects were presented and transferred to a reference simulation case. This allowed testing and for the first time a comparison of all approaches at the same

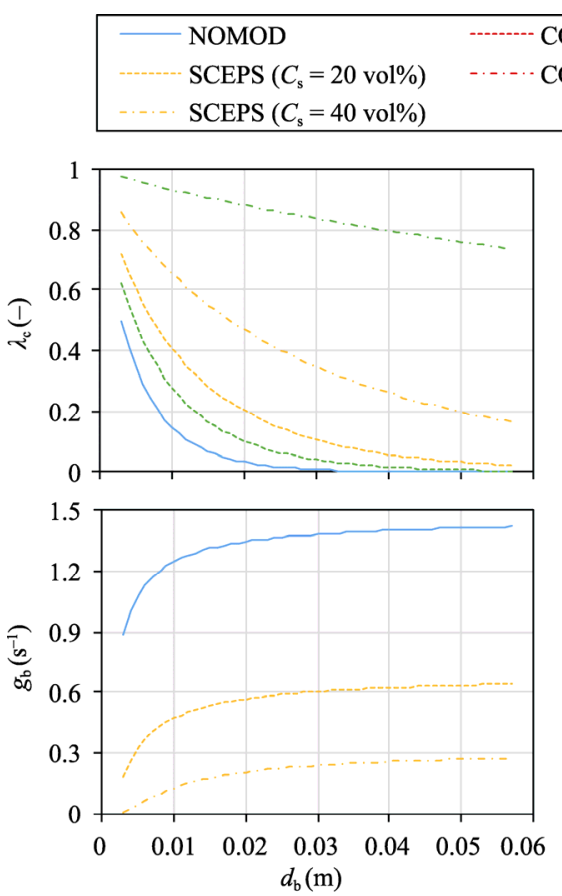

$\operatorname{COPAA}\left(C_{\mathrm{s}}=20 \mathrm{vol} \%\right)$
$\operatorname{COPAA}\left(C_{\mathrm{s}}=40 \mathrm{vol} \%\right)$


conditions for two superficial gas velocities $U_{\mathrm{g}}$ and a wide range of solid-particle concentrations $c_{s}$.

The COPAA approach accounts for enhanced coalescence by adapting an empirical parameter in the model for the collision frequency $h_{\mathrm{c}}$. It can be applied for different material systems such as different solid-particle concentrations $c_{\mathrm{s}}$. The SEM approach modifies solely the coalescence efficiency $\lambda_{c}$ by artificially lowering the ratio of the film drainage time $t_{i j}$ and the bubble contact time $\tau_{i j}$ with a multiplier $\beta$. The value of $\beta$ can be derived from film rupture measurements and is dependent on solid-particle diameter and concentration. Within the SCEPS approach, the dissipation rate of the turbulent kinetic energy $\varepsilon$ is reduced with an attenuation factor due to the presence of small solid particles based on findings of DNS. The modified dissipation rate acts on the models for coalescence and breakup where the breakup rate $g_{\mathrm{b}}$ is lowered and the coalescence frequency $\Gamma_{c}$ increased.

The capabilities of all approaches were confirmed for $c_{\mathrm{s}}=20 \mathrm{vol} \%$ for both superficial gas velocities $U_{\mathrm{g}}=$ 0.020 and $0.034 \mathrm{~m} / \mathrm{s}$ and improved the simulation results when compared to experimental data. Limitations occur with a high solid-particle concentration $c_{\mathrm{s}}=40 \mathrm{vol} \%$ : The SCEPS approach slightly overestimates the measured gas holdup for $U_{\mathrm{g}}=0.020 \mathrm{~m} / \mathrm{s}$ and the SEM approach underestimates the gas holdup for $U_{\mathrm{g}}=0.034 \mathrm{~m} / \mathrm{s}$. The COPAA approach is able to improve the simulated results for all investigated $c_{\mathrm{s}}$ and $U_{\mathrm{g}}$ but has to be calibrated for different $c_{\mathrm{s}}$.

Additionally, the effects of the applied approaches on the bubble velocities, BSD, and the respective Sauter mean diameters were studied. These quantities could not be validated due to missing experimental data but served for discussion and allowed deeper insights into the effects of the various approaches. Therefore, future studies tackle setting up an experimental data base to validate also simulation results of bubble size distributions and velocities in slurry bubble columns. Finally, only the validation of these quantities will lead to a better understanding of the physics and a more standardized formulation of the modification approaches to account for solid-particle effects on bubble breakup and coalescence.

\section{Acknowledgements}

The authors acknowledge the financial support from the Deutsche Forschungsgemeinschaft (DFG) funded Research Training Group RTG 1932 "Stochastic Models for Innovations in the Engineering Sciences". In addition, gratitude is given to the Allianz für Hochleistungsrechnen Rheinland-Pfalz (AHRP) and Regionales Hochschulrechenzentrum Kaiserslautern (RHRK) for providing the resources on the highperformance cluster "Elwetritsch". Special thanks are due to
Helmholtz-Zentrum Dresden-Rossendorf (HZDR) for the invitation and the encouragement to focus on the topic and to work everything out persistently.

\section{Funding note}

Open Access funding enabled and organized by Projekt DEAL.

\section{References}

Abdullah, H. M. 2019. Study of axial solid concentration distribution in slurry bubble columns. Energy Procedia, 157: 1537-1545.

An, M., Guan, X., Yang, N. 2020. Modeling the effects of solid particles in CFD-PBM simulation of slurry bubble columns. Chem Eng Sci, 223: 115743.

Baird, M. H. I., Rice, R. G. 1975. Axial dispersion in large unbaffled columns. Chem Eng J, 9: 171-174.

Behkish, A., Lemoine, R., Oukaci, R., Morsi, B. I. 2006. Novel correlations for gas holdup in large-scale slurry bubble column reactors operating under elevated pressures and temperatures. Chem Eng J, 115: 157-171.

Burns, A. D., Frank, T., Hamill, I., Shi, J. M. 2004. The Favre averaged drag model for turbulent dispersion in Eulerian multi-phase flows. In: Proceedings of the 5th International Conference on Multiphase Flow, 1-17.

Chen, P., Sanyal, J., Dudukovic, M. P. 2004. CFD modeling of bubble columns flows: Implementation of population balance. Chem Eng Sci, 59: 5201-5207.

Chen, Z., Grace, J. R., Lim, J. C. 2008. Limestone particle attrition and size distribution in a small circulating fluidized bed. Fuel, 87: 1360-1371.

Davidson, J. F., Schüler, B. O. 1960. Bubble formation at an orifice in an inviscid liquid. Trans Inst Chem Eng, 38: 335-342.

Deckwer, W.-D., Schumpe, A. 1985. Blasensälen - erkenntnisstand und entwicklungstendenzen. Chem Ing Tech, 57: 754-767.

Fan, L.-S. 1989. Gas-Liquid-Solid Fluidization Engineering. Boston: Butterworths.

Fan, L.-S., Hemminger, O., Yu, Z., Wang, F. 2007. Bubbles in nanofluids. Ind Eng Chem Res, 46: 4341-4346.

Gidaspow, D. 1994. Multiphase Flow and Fluidization: Continuum and Kinetic Theory Descriptions. San Diego: Elsevier Science.

Hounslow, M. J., Ryall, R. L., Marshall, V. R. 1988. A discretized population balance for nucleation, growth, and aggregation. AIChE J, 34: 1821-1832.

Jakobsen, H. A. 2014. Chemical Reactor Modeling: Multiphase Reactive Flows, 2nd edn. Cham: Springer.

Jiang, X., Yang, N., Yang, B. 2016. Computational fluid dynamics simulation of hydrodynamics in the riser of an external loop airlift reactor. Particuology, 27: 95-101.

Krishna, R., de Swart, J. W. A., Ellenberger, J., Martina, G. B., Maretto, 
C. 1997. Gas holdup in slurry bubble columns: Effect of column diameter and slurry concentrations. AIChE J, 43: 311-316.

Laakkonen, M., Alopaeus, V., Aittamaa, J. 2006. Validation of bubble breakage, coalescence and mass transfer models for gas-liquid dispersion in agitated vessel. Chem Eng Sci, 61: 218-228.

Laakkonen, M., Moilanen, P., Alopaeus, V., Aittamaa, J. 2007. Modelling local bubble size distributions in agitated vessels. Chem Eng Sci, 62: 721-740.

Li, H., Prakash, A. 2000. Influence of slurry concentrations on bubble population and their rise velocities in a three-phase slurry bubble column. Powder Technol, 113: 158-167.

Luo, X., Lee, D. J., Lau, R., Yang, G., Fan, L.-S. 1999. Maximum stable bubble size and gas holdup in high-pressure slurry bubble columns. AIChE J, 45: 665-680.

MacIntyre, S., Hammad, A., Pjontek, D. 2017. Particle agglomeration studies in a slurry bubble column due to liquid bridging: Effects of particle size and sparger design. Chem Eng Sci, 170: 213-224.

Mokhtari, M., Chaouki, J. 2019. New technique for simultaneous measurement of the local solid and gas holdup by using optical fiber probes in the slurry bubble column. Chem Eng J, 358: 831-841.

Mühlbauer, A., Hlawitschka, M. W., Bart, H.-J. 2019. Models for the numerical simulation of bubble columns: A review. Chem Ing Tech, 91: 1747-1765.

Ojima, S., Hayashi, K., Tomiyama, A. 2014. Effects of hydrophilic particles on bubbly flow in slurry bubble column. Int $J$ Multiphase Flow, 58: 154-167.

Ojima, S., Sasaki, S., Hayashi, K., Tomiyama, A. 2015. Effects of particle diameter on bubble coalescence in a slurry bubble column. J Chem Eng Jpn, 48: 181-189.

Prince, M. J., Blanch, H. W. 1990. Bubble coalescence and break-up in air-sparged bubble columns. AIChE J, 36: 1485-1499.

Rzehak, R., Krepper, E., Liao, Y., Ziegenhein, T., Kriebitzsch, S., Lucas, D. 2015. Baseline model for the simulation of bubbly flows. Chem Eng Technol, 38: 1972-1978.

Rzehak, R., Kriebitzsch, S. 2015. Multiphase CFD-simulation of bubbly pipe flow: A code comparison. Int J Multiphase Flow, 68: $135-152$.

Sarhan, A. R., Naser, J., Brooks, G. 2018. Effects of particle size and concentration on bubble coalescence and froth formation in a slurry bubble column. Particuology, 36: 82-95.

Schäfer, J., Hlawitschka, M. W., Attarakih, M. M., Bart, H.-J. 2019. Experimental investigation of local bubble properties: Comparison to the sectional quadrature method of moments. AIChE J, 65: e16694.

Shah, Y. T., Kelkar, B. G., Godbole, S. P., Deckwer, W.-D. 1982. Design parameters estimations for bubble column reactors. AIChE J, 28: 353-379.

Sines, J. N., Hwang, S., Marashdeh, Q. M., Tong, A., Wang, D., He, P., Straiton, B. J., Zuccarelli, C. E., Fan, L.-S. 2019. Slurry bubble column measurements using advanced electrical capacitance volume tomography sensors. Powder Technol, 355: 474-480.
Squires, K. D., Eaton, J. K. 1994. Effect of selective modification of turbulence on two-equation models for particle-laden turbulent Flows. J Fluids Eng, 116: 778-784.

Sundaram, S., Collins, L. R. 1999. A numerical study of the modulation of isotropic turbulence by suspended particles. $J$ Fluid Mech, 379: 105-143.

Syed, A. H., Boulet, M., Melchiori, T., Lavoie, J.-M. 2018. CFD simulation of a slurry bubble column: Effect of population balance kernels. Comput Fluids, 175: 167-179.

Tabib, M. V., Roy, S. A., Joshi, J. B. 2008. CFD simulation of bubble column-An analysis of interphase forces and turbulence models. Chem Eng J, 139: 589-614.

Tomiyama, A. 1998. Struggle with computational bubble dynamics. Multiphase Sci Technol, 10: 369-405.

Tomiyama, A., Kataoka, I., Fukuda, T., Sakaguchi, T. 1995. Drag coefficients of bubbles. 2nd report. drag coefficient for a swarm of bubbles and its applicability to transient flow. Trans Jpn Soc Mech Eng B, 61: 2810-2817.

Tomiyama, A., Kataoka, I., Zun, I., Sakaguchi, T. 1998. Drag coefficients of single bubbles under normal and micro gravity conditions. JSME Int J Ser B, 41: 472-479.

Tomiyama, A., Tamai, H., Zun, I., Hosokawa, S. 2002. Transverse migration of single bubbles in simple shear flows. Chem Eng Sci, 57: $1849-1858$.

Troshko, A. A., Zdravistch, F. 2009. CFD modeling of slurry bubble column reactors for Fisher-Tropsch synthesis. Chem Eng Sci, 64: 892-903.

Tyagi, P., Buwa, V. V. 2017. Dense gas-liquid-solid flow in a slurry bubble column: Measurements of dynamic characteristics, gas volume fraction and bubble size distribution. Chem Eng Sci, 173: 346-362.

Vakhrushev, I. A., Efremov, G. I. 1970. Interpolation formula for computing the velocities of single gas bubbles in liquids. Chem Technol Fuels Oils, 6: 376-379.

Van der Zon, M., Hamersma, P. J., Poels, E. K., Bliek, A. 2002. Coalescence of freely moving bubbles in water by the action of suspended hydrophobic particles. Chem Eng Sci, 57: 4845-4853.

Vandu, C. O., Krishna, R. 2004. Volumetric mass transfer coefficients in slurry bubble columns operating in the churn-turbulent flow regime. Chem Eng Process Process Intensif, 43: 987-995.

Vik, C. B., Solsvik, J., Hillestad, M., Jakobsen, H. A. 2018. Interfacial mass transfer limitations of the Fischer-Tropsch synthesis operated in a slurry bubble column reactor at industrial conditions. Chem Eng Sci, 192: 1138-1156.

Wang, T. 2011. Simulation of bubble column reactors using CFD coupled with a population balance model. Front Chem Sci Eng, 5: 162-172.

Weller, H., Greenshields, C., de Rouvray, C. 2018. OpenFOAM v6. London, United Kingdom: The OpenFOAM Foundation Ltd. Available at https://openfoam.org/version/6/. 
Xu, L., Xia, Z., Guo, X., Chen, C. 2014. Application of population balance model in the simulation of slurry bubble column. Ind Eng Chem Res, 53: 4922-4930.

Zhang, D., Deen, N. G., Kuipers, J. A. M. 2006. Numerical simulation of the dynamic flow behavior in a bubble column: A study of closures for turbulence and interface forces. Chem Eng Sci, 61: 7593-7608.

Zhou, R., Yang, N., Li, J. 2017. CFD simulation of gas-liquid-solid flow in slurry bubble columns with EMMS drag model. Powder Technol, 314: 466-479.

Open Access This article is licensed under a Creative Commons Attribution 4.0 International License, which permits use, sharing, adaptation, distribution and reproduction in any medium or format, as long as you give appropriate credit to the original author(s) and the source, provide a link to the Creative Commons licence, and indicate if changes were made.

The images or other third party material in this article are included in the article's Creative Commons licence, unless indicated otherwise in a credit line to the material. If material is not included in the article's Creative Commons licence and your intended use is not permitted by statutory regulation or exceeds the permitted use, you will need to obtain permission directly from the copyright holder.

To view a copy of this licence, visit http://creativecommons.org/licenses/by/4.0/. 